\title{
Glucose Metabolism Distal to a Critical Coronary Stenosis in a Canine Model of Low-Flow Myocardial Ischemia
}

\author{
Patrick H. McNulty, Albert J. Sinusas, Cindy Q.-X. Shi, Donald Dione, Lawrence H. Young, Gary C. Cline, \\ and Gerald I. Shulman \\ Department of Internal Medicine, VA Connecticut Medical Center and Yale University School of Medicine, New Haven, \\ Connecticut 06520
}

\begin{abstract}
Myocardial regions perfused through a coronary stenosis may cease contracting, but remain viable. Clinical observations suggest that increased glucose utilization may be an adaptive mechanism in such "hibernating" regions. In this study, we used a combination of ${ }^{13} \mathrm{C}$-NMR spectroscopy, GC-MS analysis, and tissue biochemical measurements to track glucose through intracellular metabolism in intact dogs infused with $\left[1-{ }^{13} \mathrm{C}\right]$ glucose during a $3-4-\mathrm{h}$ period of acute ischemic hibernation.

During low-flow ischemia $\left[3-{ }^{13} \mathrm{C}\right]$ alanine enrichment was higher, relative to plasma $\left[1{ }^{13} \mathrm{C}\right]$ glucose enrichment, in ischemic than in nonischemic regions of the heart, suggesting a greater contribution of exogenous glucose to glycolytic flux in the ischemic region $(\sim 72$ vs. $\sim 28 \%, P<0.01)$. Both the fraction of glycogen synthase present in the physiologically active glucose-6-phosphate-independent form $(46 \pm$ 10 vs. $9 \pm 6 \%, P<0.01$ ) and the rate of incorporation of circulating glucose into glycogen $(94 \pm 25$ vs. $20 \pm 15 \mathrm{nmol} /$ gram/min, $P<0.01$ ) were also greater in ischemic regions. Measurement of steady state $\left[4-{ }^{13} \mathrm{C}\right]$ glutamate/[3- $\left.{ }^{13} \mathrm{C}\right]$ alanine enrichment ratios demonstrated that glucose-derived pyruvate supported $26-36 \%$ of total tricarboxylic acid cycle flux in all regions, however, indicating no preference for glucose over fat as an oxidative substrate in the ischemic myocardium. Thus during sustained regional low-flow ischemia in vivo, the ischemic myocardium increases its utilization of exogenous glucose as a substrate. Upregulation is restricted to cytosolic utilization pathways, however (glycolysis and glycogen synthesis), and fat continues to be the major source of mitochondrial oxidative substrate. (J. Clin. Invest. 1996. 98:62-69.) Key words: glycogen • coronary artery disease $\bullet$ hibernation $\cdot$ glycolysis $\bullet$ NMR spectroscopy
\end{abstract}

\section{Introduction}

In patients with ischemic heart disease, myocardial regions perfused through a critically narrowed coronary artery may lose the ability to contract, yet remain viable for prolonged pe-

Address correspondence to Patrick H. McNulty, M.D., Cardiology/ 111B, VA Connecticut Medical Center, 950 Campbell Avenue, West Haven, CT 06516. Phone: 203-932-5711x3391; FAX: 203-937-3884.

Received for publication 23 January 1996 and accepted in revised form 4 April 1996.

J. Clin. Invest.

(C) The American Society for Clinical Investigation, Inc.

0021-9738/96/07/62/08 \$2.00

Volume 98, Number 1, July 1996, 62-69 riods (1). These underperfused "hibernating" regions presumably follow successful strategies for preserving cellular viability during ischemia. Distinguishing such regions from nonviable myocardium is moreover of significant practical importance to the clinician. Nevertheless, the metabolic adaptation to reduced coronary flow remains incompletely understood.

In the experimental setting, reducing coronary blood flow acutely lowers tissue concentrations of high-energy phosphates, stimulates glycogen breakdown and glycolysis, increases lactate production, and abolishes contraction (2-7). However, over time lactate production diminishes, and highenergy phosphate concentrations stabilize (4) or even recover (3), as the ischemic myocardium downregulates its energy expenditures to match the reduced rate of production. While downregulation of myocardial energy consumption is undoubtedly an important adaptive response to reduced coronary flow, continued myocardial viability necessarily requires the operation of energy-generating processes in an environment that may be characterized by low oxygen tension, acidic $\mathrm{pH}$, or other metabolic abnormalities. How these processes compare with those operating in the aerobic myocardium is not known. However, both theoretical considerations and empiric observations suggest that the myocardium may increase its uptake and utilization of glucose under such conditions (8-12).

Glucose imported into the heart is metabolized via three principal pathways: (a) glycolysis ending in lactic acid formation; $(b)$ glycolytic production of pyruvate, with subsequent flux through pyruvate dehydrogenase $(\mathrm{PDH})^{1}$ to complete oxidation in the tricarboxylic acid (TCA) cycle; and (c) storage as glycogen. These pathways differ significantly in their quantitative contribution to cellular energy production. Furthermore, evidence suggests that myocardial energy metabolism may be compartmentalized, such that ATP generated in the cytosol via glycolysis may be more readily available for use by processes presumably important for cellular viability (e.g., ion transport [13]), than ATP generated oxidatively in mitochondria $(13,14)$. Thus it would seem important to understand how glucose imported into the underperfused myocardium is partitioned among various potential utilization pathways. Indeed, this point is illustrated by recent observations that glycogen concentration is increased in chronically underperfused, hibernating regions of the diseased human heart (15-17), raising the possibility that glucose imported into such regions may be diverted away from energy generating pathways altogether, and toward storage.

1. Abbreviations used in this paper: APE, atoms percent excess; GS I, glucose-6-phosphate independent; LAD, left anterior descending; LCX, left circumflex; PDH, pyruvate dehydrogenase; TCA, tricarboxylic acid. 
Recently, it has become possible to examine myocardial metabolism using ${ }^{13} \mathrm{C}-\mathrm{NMR}$ spectroscopy in the isolated heart perfused with defined mixtures of ${ }^{13} \mathrm{C}$-labeled substrates. With this technique, hearts perfused aerobically with $\left[1{ }^{13} \mathrm{C}\right]$ glucose accumulate $\left[3-{ }^{13} \mathrm{C}\right]$ alanine and $\left[4-{ }^{13} \mathrm{C}\right]$ glutamate in proportion to rates of glycolysis and glucose-supported TCA cycle activity, respectively (18). Furthermore, the steady state $\left[4-{ }^{13} \mathrm{C}\right]$ glutamate/[3- $\left.{ }^{13} \mathrm{C}\right]$ alanine enrichment ratio can be used to estimate the proportion of TCA cycle activity supported by glucose flux through the PDH complex, relative to that supported by free fatty acids (FFA) or other substrates (19-21). This quantity may be particularly important to know in the ischemic myocardium. Both Kobayashi (22), using traditional biochemistry in the isolated perfused rat heart, and Lewandowski (23), using ${ }^{13} \mathrm{C}-\mathrm{NMR}$ spectroscopy in the perfused rabbit heart, have observed concordant impairment in $\mathrm{PDH}$ activity and contractility in the ischemic setting and have demonstrated that stimulating $\mathrm{PDH}$ improves mechanical function.

While ${ }^{13} \mathrm{C}$-NMR studies of isolated buffer-perfused hearts have provided useful insights, the use of nonphysiologic perfusate compositions, perfusion rates, and work loads in such preparations makes extrapolation to the clinical situation difficult, nor can ischemic hibernation be adequately modeled in the isolated heart. Accordingly, in this study we combined ${ }^{13} \mathrm{C}$ NMR spectroscopy with tissue biochemical analysis to examine the metabolic fate of glucose imported into the heart in a clinically relevant canine model of acute regional ischemic hibernation. We specifically addressed three questions: first, whether NMR spectroscopy can be used to track circulating ${ }^{13} \mathrm{C}$-glucose through glycolytic and oxidative pathways in the hearts of intact large animals; second, whether sustained lowflow ischemia increases the fraction of TCA cycle activity supported by pyruvate, relative to FFA, within the hibernating region (that is, whether ischemia shifts myocardial oxidative substrate preference from FFA to glucose); and third, whether ischemia alters glycogen metabolism in a manner which might explain the increased glycogen content of chronically hibernating myocardium in patients with coronary artery disease.

\section{Methods}

\section{Experimental preparation}

17 mongrel dogs of either sex, weighing $20-30 \mathrm{~kg}$, were studied after an overnight fast. All experimental procedures were approved by the Animal Care and Use Committee of the Yale University School of Medicine. Animals were anesthetized with thiomalol sodium $(25 \mathrm{mg} /$ $\mathrm{kg}$, i.v.) and mechanically ventilated. General anesthesia was maintained with nitrous oxide/oxygen (3:1) and halothane (1.0-1.5\%). Oxygenation and ventilation were monitored by periodic measurement of arterial blood gasses. Core temperature was measured with a thermistor positioned in the right atrium and maintained between $34^{\circ} \mathrm{C}$ and $37^{\circ} \mathrm{C}$ using a heating blanket and insulating wraps.

The heart was exposed through a left lateral thoracotomy and suspended in a pericardial cradle. The left anterior descending (LAD) coronary artery was encircled with a hydraulic occluder as far proximally on the LAD as the anatomy of side branches would allow. A catheter was inserted into a distal LAD branch to monitor distal perfusion pressure. Other catheters were placed into veins draining the LAD and left circumflex (LCX) coronary perfusion beds for regional venous blood sampling, the abdominal aorta for arterial blood sampling and recording systemic arterial pressure, and the left atrium for infusion of isotopes or radioactive microspheres. Doppler crystals (Crystal Biotech, Hopkinton, MA) were sewn to the epicardium of the central LAD and LCX perfusion beds to record regional transmural systolic thickening. The surgical preparation has been reported in detail previously (24).

\section{Experimental protocol}

Regional low-flow myocardial ischemia protocol. After surgical preparation, dogs were divided into two groups. Group $1(n=11)$ was used for all metabolic measurements. To avoid possible interference with measurement of tissue ${ }^{3} \mathrm{H}$ activity in group 1 , a separate group of identically prepared dogs (group $2, n=6$ ) was used to define myocardial blood flow with radioactive microspheres. Basal measurements were made of distal LAD perfusion pressure, systolic thickening in the LAD and LCX regions, and the lactate concentration of aortic, LAD venous, and LCX venous blood. The hydraulic occluder was then inflated to reduce mean distal LAD pressure to approximately one-half that of the aorta, for either $3(n=8)$ or $4(n=3)$ h. 4-h experiments were performed to allow a longer period for isotopic equilibration, as described below. Regional systolic thickening and arteriovenous lactate balance were measured at intervals during the LAD stenosis to characterize the low-flow ischemic state.

${ }^{13} \mathrm{C}$-Labeling of plasma glucose and intracellular glucose metabolites. During LAD stenosis, $99 \%$ enriched $\mathrm{D}-\left[1-{ }^{13} \mathrm{C}\right]$ glucose (ISOTEC, Miamisburg, $\mathrm{OH}$ ), reconstituted as a $20 \%$ solution in water, was infused into the left atrium at a rate of $1.0 \mathrm{mg} / \mathrm{kg} / \mathrm{min}$. This rate was chosen to achieve maximum ${ }^{13} \mathrm{C}$ enrichment of plasma glucose and its intracellular metabolites, without significantly altering the plasma glucose concentration. In eight dogs, ${ }^{13} \mathrm{C}$-glucose was infused for the final $2 \mathrm{~h}$ of a 3-h period of LAD stenosis. In the three remaining dogs, to control for potential regional differences in the rate of isotopic equilibration between plasma and intracellular carbon pools, the LAD stenosis was extended to $4 \mathrm{~h}$ and ${ }^{13} \mathrm{C}$-glucose was infused for either the final $3 \mathrm{~h}(n=2)$ or the entire $4 \mathrm{~h}(n=1)$ of ischemia. Arterial plasma was collected at 15 -min intervals during ${ }^{13} \mathrm{C}$-glucose infusion for measurement of chemical glucose concentration and $\left[1-{ }^{13} \mathrm{C}\right]$ glucose fractional enrichment.

Measurement of regional myocardial glycogen synthesis. A subset of four dogs in group 1 also received a trace intravenous infusion of D- $\left[3-{ }^{3} \mathrm{H}\right]$ glucose $(5 \mu \mathrm{Ci} / \mathrm{min})$ during the final hour of low-flow ischemia, to label newly synthesized glycogen in the LAD and LCX regions. In these dogs, $0.5 \mathrm{ml}$ of whole blood was collected at 10-min intervals during ${ }^{3} \mathrm{H}$-glucose infusion, deproteinized by diluting $1: 1$ with an ice-cold solution of $10 \%$ trichloroacetic acid, and the acid supernatant saved for measurement of whole blood ${ }^{3} \mathrm{H}$-glucose specific radioactivity $(25,26)$.

At the conclusion of each experiment the heart was quickly excised. Care was taken to continue ${ }^{13} \mathrm{C}$ - and ${ }^{3} \mathrm{H}$-glucose infusions and to maintain the LAD stenosis, until the actual moment of excision. Central portions ( $\sim 4$ grams) of the ischemic LAD and control LCX perfusion beds were rapidly excised, divided into epicardial and endocardial halves, and frozen by clamping between aluminum blocks chilled in liquid nitrogen. This resulted in four tissue samples for each heart, which are referred to as anterior endocardium, anterior epicardium, posterior endocardium, and posterior epicardium. All tissue and plasma samples were stored at $-80^{\circ} \mathrm{C}$.

Measurement of myocardial blood flow. In the six dogs in group 2, radioactive microspheres were injected into the left atrium before applying the LAD stenosis, and again after 60 and $120 \mathrm{~min}$ of ischemia. After $4 \mathrm{~h}$ of low-flow ischemia, hearts were sectioned transversely, stained with triphenyltetrazolium chloride to exclude the presence of myocardial necrosis, and regional myocardial blood flow calculated as described previously (27).

\section{Analytical methods}

Plasma glucose, lactate and insulin concentration, and lactate arteriovenous balance. Glucose concentration $(\mathrm{mM})$ in plasma and in trichloroacetic acid extracts of whole blood was measured using an enzymatic method (28). Plasma insulin was measured using a double antibody radioimmunoassay. Arterial and coronary venous blood lac- 
tate concentrations $(\mathrm{mM})$ were determined using an automated lactate oxidase analyzer (YSI analyzer; Yellow Springs Instrument Co., Yellow Springs, $\mathrm{OH})$. Lactate extraction $(\mu \mathrm{mol} / \mathrm{ml})$ across the LAD and LCX regions was calculated by subtracting the coronary venous from the arterial concentration; percent extraction was calculated by dividing this arterial-minus-venous lactate concentration difference by arterial lactate concentration, and multiplying by 100 .

Plasma and tissue ${ }^{13} \mathrm{C}$ enrichments. Tissue preparation: Amino acids were extracted from $\sim 1.0$ gram of frozen myocardium by homogenization in cold $6 \%$ perchloric acid. Alanine, aspartate, glutamate, and lactate were purified by means of a $0.9 \times 150 \mathrm{~cm}$ Dowex-50 (200-400 mesh) column equilibrated with ammonium formate (0.1 M, $\mathrm{pH} 3.0)$ as described previously (21). The absolute ${ }^{13} \mathrm{C}$ enrichments at each carbon position (except the carboxyl carbons, which were assumed to be present at natural abundance) were determined algebraically from the relative enrichment at each carbon (determined from the ${ }^{13} \mathrm{C}$-NMR spectra) and the absolute total enrichment (determined from GC-MS analysis).

NMR methodology: ${ }^{13} \mathrm{C}$-NMR spectra were acquired at 125.76 $\mathrm{MHz}$ (AM 500; Bruker Instruments, Inc., Billerica, MA) using a standard ${ }^{13} \mathrm{C} /{ }^{1} \mathrm{H}$ probe. Briefly, spectra were acquired using a $30^{\circ}$ pulse, quadrature detection, digital resolution of $2.7 \mathrm{~Hz} /$ point, and with a pulse program for inverse-gated heteronuclear WALTZ decoupling with a delay of $1 \mathrm{~s}$ between pulses.

GC-MS methodology: GC-MS analysis was performed with a gas chromatograph (HP-1 capillary column, $12 \mathrm{~mm} \times 0.2 \mathrm{~mm} \times 0.33 \mu \mathrm{m}$ film thickness; model 5890, Hewlett-Packard Co., Palo Alto, CA) interfaced to a HP 5971A mass selective detector operating in the positive chemical ionization mode with methane as reagent gas. Glucose was derivatized as the pentaacetate, and isotopic enrichment determined from the ion intensities of $\mathrm{m} / \mathrm{z} 331$ to 334 . Amino acids were derivatized and analyzed by GC-MS as the trifluoroacetyl $n$-butyl ester (29). Isotopic enrichment of alanine was determined from the ion intensities of $\mathrm{m} / \mathrm{z} 242$ to 247 , aspartate from $\mathrm{m} / \mathrm{z} 342$ to 348 , and glutamate $\mathrm{m}+1$ to $\mathrm{m}+5$ from $\mathrm{m} / \mathrm{z} 356$ to 363 .

Regional glycogen concentration and glycogen synthesis rate. Duplicate small portions ( $\sim 100 \mathrm{mg}$ ) of each frozen tissue sample were assayed for glycogen by potassium hydroxide solubilization, ethanol precipitation, and amyloglucosidase digestion, as described previously $(25,26)$. Duplicate results were averaged and expressed as $\mu$ mol glucose per gram wet weight of tissue.

For the four dogs infused with ${ }^{3} \mathrm{H}$-glucose, acid extracts of whole blood were counted for glucose ${ }^{3} \mathrm{H}$ radioactivity by liquid scintillation spectrophotometry, after air drying to remove $\left[{ }^{3} \mathrm{H}\right] \mathrm{H}_{2} \mathrm{O}$. Specific radioactivity $(\mathrm{dpm} / \mu \mathrm{mol})$ was calculated by dividing these counts by the glucose content of each sample. Each dog's average specific radioactivity during ${ }^{3} \mathrm{H}$-glucose infusion was then determined by the trapezoidal method (26).

Rates of incorporation of circulating glucose into glycogen ( $\mu \mathrm{mol} /$ gram $/ \mathrm{min}$ ) in each myocardial region were determined by dividing the ${ }^{3} \mathrm{H}$ radioactivity of each prepared glycogen sample by the product of average blood specific radioactivity, tissue weight, and ${ }^{3} \mathrm{H}$-glucose infusion time $(25,26)$

Glycogen synthase and phosphorylase activities. Samples $(50-60 \mathrm{mg})$ of frozen myocardium were homogenized at $4^{\circ} \mathrm{C}$ in a solution of 150 $\mu \mathrm{mol} / \mathrm{liter}$ potassium fluoride, $30 \mu \mathrm{mol} / \mathrm{liter}$ EDTA, and $30 \%$ (wt/ vol) glycerol, and centrifuged at 5,000 $\mathrm{g}$. Supernatants were used to assay glycogen synthase and phosphorylase activities by modifications of the procedures of Thomas (30) and of Tan (31), respectively, as described previously $(25,26)$.

Glycogen synthase activity was measured at low $(0.17 \mu \mathrm{mol} / \mathrm{liter})$ and saturating $(7.2 \mu \mathrm{mol} /$ liter $)$ concentrations of its activator glucose6-phosphate. Activity at $0.17 \mu \mathrm{mol} /$ liter is referred to as glucose-6phosphate independent (GS I) and is considered the physiologic activity of the enzyme, while that at $7.2 \mu \mathrm{mol} /$ liter glucose-6-phosphate is considered total activity. Glycogen phosphorylase activity was similarly measured in the absence (GPa activity) or presence (total GP activity) of $5 \mu \mathrm{mol} /$ liter adenosine monophosphate.

\section{Data analysis}

Lactate arterial-venous concentration differences at each time point were examined for significance using paired Student's $t$ tests. Trends between time points were tested by repeated measures ANOVA. Comparisons between myocardial regions were made using one-way ANOVA. Unless stated otherwise, all data are presented as mean \pm SEM.

\section{Results}

Hemodynamics. Hemodynamic measurements in group 1 and 2 dogs are summarized in Table I. As can be seen, the group used to measure myocardial blood flow did not differ significantly from the group used to characterize substrate metabolism.

Regional myocardial blood flow. None of the six dogs in group 2 exhibited myocardial necrosis by ex vivo triphenyltetrazolium chloride staining. Results of myocardial blood flow measurements are shown in Table II. LAD stenosis reduced blood flow in the endocardial layer of the anterior left ventricle by $\sim 50 \%$, while having minimal effect on overall epicardial flow, thus reducing transmural flow by $\sim 25 \%$. Blood flow in the control posterior left ventricle was slightly higher than basal $60 \mathrm{~min}$ into the LAD stenosis, but by $120 \mathrm{~min}$ was not different than basal.

Regional perfusion pressure, contractile function, and arteriovenous lactate balance. Fig. 1 shows relevant functional and metabolic characteristics of hearts in group 1 dogs. In the basal state, mean pressure in the distal LAD and aorta were equal, the LAD and LCX regions each exhibited transmural systolic thickening, and the heart extracted $25 \pm 5 \%$ of arterial blood lactate. LAD stenosis lowered distal LAD perfusion pressure by $50 \%$ and reduced systolic thickening in the LAD region to $2 \pm 3 \%$ of basal, while LCX region thickening tended to increase slightly. LAD stenosis also converted arteriovenous lactate balance across the LAD region from net extraction to neutral (i.e., arterial-minus-venous lactate concentration not significantly different from zero). While there was a trend toward relatively lower LAD coronary venous lactate concentra-

Table I. Hemodynamic Parameters in Group 1 and Group 2 Dogs

Basal HR Ischemic HR Basal MAP Ischemic MAP Basal MLADP Ischemic MLADP Basal LCX-TH Ischemic LCX-TH Basal LAD-TH Ischemic LAD-TH

$\min$

Group 1 104+16

$104 \pm 16 \quad 110 \pm 18$

$\min ^{-1}$
Group 2 114 15
$\mathrm{mmHg}$

$\mathrm{mmHg}$

$\mathrm{mmHg}$

$\mathrm{mmHg}$

$93 \pm 11$

$102 \pm 26$

$51 \pm 8 *$

$58 \pm 15 *$

$101 \pm 13$
$95+26$

$\%$

$\%$

$13 \pm 7$

$12 \pm 4$

$15 \pm 5$

$\%$

$\%$

$\%$

Hemodynamic data (mean \pm SD) for group $1(n=11)$ and group $2(n=6)$ dogs. There were no differences between the groups for any individual parameter. ${ }^{*} P<0.05$ vs. basal value. $H R$, heart rate; $M A P$, mean aortic pressure; $M L A D P$, mean LAD pressure; $L A D-T H$, percent systolic thickening in the LAD coronary region; $L C X-T H$, percent systolic thickening in the LCX coronary region. 


\begin{tabular}{|c|c|c|c|c|c|c|}
\hline & \multicolumn{3}{|c|}{ Anterior } & \multicolumn{3}{|c|}{ Posterior } \\
\hline & Endocardial & Epicardial & Transmural & Endocardial & Epicardial & Transmural \\
\hline Basal & $0.83 \pm 0.11$ & $1.05 \pm 0.11$ & $0.92 \pm 0.10$ & $0.85 \pm 0.10$ & $0.84 \pm 0.09$ & $0.85 \pm 0.10$ \\
\hline 60-min ischemia & $0.44 \pm 0.05^{*}$ & $1.20 \pm 0.14$ & $0.85 \pm 0.10$ & $1.21 \pm 0.13^{*}$ & $1.25 \pm 0.14 *$ & $1.22 \pm 0.13^{*}$ \\
\hline 120 -min ischemia & $0.36 \pm 0.05 *$ & $0.93 \pm 0.08$ & $0.68 \pm 0.08 *$ & $0.98 \pm 0.10$ & $0.92 \pm 0.06$ & $0.94 \pm 0.08$ \\
\hline
\end{tabular}

Regional myocardial blood flow, in $\mathrm{ml} / \mathrm{min} /$ gram wet weight tissue, measured by radioactive microsphere injection basally, and after 1 or $2 \mathrm{~h}$ of LAD coronary stenosis. Values represent mean $\pm \mathrm{SD}$ for four $\operatorname{dogs}$ each. $* P<0.05$ vs. basal value for the same region.

tions during the final hour of ischemia, net extraction did not resume.

Plasma and tissue ${ }^{13} \mathrm{C}$ labeling. Infusion of $\mathrm{D}-\left[1-{ }^{13} \mathrm{C}\right] \mathrm{glucose}$ at $1 \mathrm{mg} / \mathrm{kg} / \mathrm{min}$ for $2 \mathrm{~h}$ increased arterial plasma glucose ${ }^{13} \mathrm{C}$ enrichment to $23.5 \pm 2.8$ atoms percent excess (APE) above natural abundance. Basal plasma glucose concentration averaged $5.5 \pm 1.0 \mathrm{mM}$, and during $\mathrm{D}-\left[1-{ }^{13} \mathrm{C}\right]$ glucose infusion ranged between 4.6 and $5.6 \mathrm{mM}$. Glucose ${ }^{13} \mathrm{C}$ enrichment did not increase much further when the infusion was extended to 3 or $4 \mathrm{~h}$
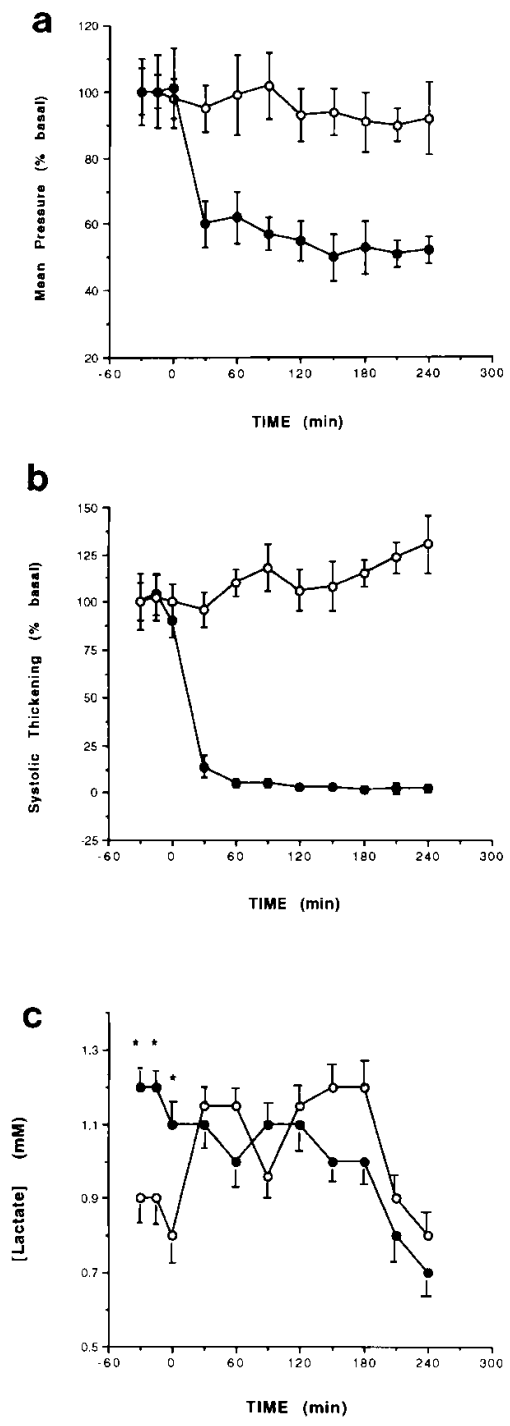

Figure 1. Values recorded basally and during 3-4 h of regional low-flow ischemia $(t=$ 0-240 min) for (a) mean arterial pressure in the aorta (open circles) and distal LAD (filled circles); (b) systolic transmural thickening in the control LCX (open circles) and ischemic LAD (filled circles) regions; (c) arterial (open circles) and LAD venous (filled circles) whole blood lactate concentrations. Mean arterial pressure and systolic thickening are expressed as a percentage of initial basal value. Data represent mean \pm SD for eight dogs at time points between $t=-30$ and $t=$ $180 \mathrm{~min}$, and for three dogs at $t=210$ and $t=$ 240 min. $* P<0.05$ vs. LAD vein.
(Table III), suggesting that plasma enrichment was nearly steady state after $2 \mathrm{~h}$. Plasma insulin concentration averaged $3.9 \pm 1.4 \mu \mathrm{U} / \mathrm{ml}$ basally and did not change $(4.2 \pm 1.9 \mu \mathrm{U} / \mathrm{ml})$ during LAD stenosis or $\mathrm{D}-\left[1-{ }^{13} \mathrm{C}\right]$ glucose infusion.

NMR analysis of myocardial acid extracts demonstrated ${ }^{13} \mathrm{C}$ labeling of the $\mathrm{C}-3$ carbons of alanine, and the C-3 and C-4 carbons of glutamate, in all 11 dogs in group 1. Fractional enrichments were lower than those of plasma glucose, ranging from 1-2.5 APE above natural abundance for glutamate C-4 to 4-9 APE for alanine C-3. Nevertheless, the alanine C-3 and glutamate $\mathrm{C}-4$ peaks could be resolved and peak areas measured in spectra from all dogs. The resulting data for glucose, alanine, and glutamate fractional ${ }^{13} \mathrm{C}$ enrichment are shown in Table III. Examination of these data revealed that after $2 \mathrm{~h}$ of $\left[1-{ }^{13} \mathrm{C}\right]$ glucose infusion, $\left[3-{ }^{13} \mathrm{C}\right]$ alanine enrichment was significantly higher in both the endocardial and epicardial layers of the anterior left ventricle than in the two posterior regions, suggesting increased relative contribution of exogenous glucose to the cellular pyruvate pool in the anterior myocardium. Average $\left[4-{ }^{13} \mathrm{C}\right]$ glutamate enrichment was also higher in the anterior regions, but this reflected simply the higher fractional enrichment of its pyruvate precursor pool, as the $\left[4-{ }^{13} \mathrm{C}\right] \mathrm{glu}-$ tamate/[3-13 C]alanine enrichment ratio did not differ significantly among regions. Extending the $\left[1-{ }^{13} \mathrm{C}\right]$ glucose infusion period to 3 or $4 \mathrm{~h}$ modestly increased the fractional enrichments of glucose, alanine, and glutamate, but did not change the $\left[4-{ }^{13} \mathrm{C}\right]$ glutamate/[3-13 C]alanine enrichment ratio of any of the regions, indicating that these pools were at steady state ${ }^{13} \mathrm{C}$ equilibrium in both ischemic and normally perfused myocardial regions after $2 \mathrm{~h}$ of $\left[1-{ }^{13} \mathrm{C}\right]$ glucose infusion.

Regional glycogen concentration. In group 1 dogs, regional

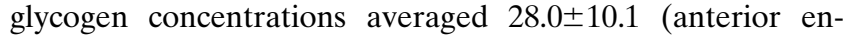
docardium), 30.5 \pm 5.2 (anterior epicardium), 33.1 \pm 10.5 (posterior endocardium), and 37.0 \pm 9.1 (posterior epicardium) $\mu \mathrm{mol} /$ gram wet weight. Results after 3 and $4 \mathrm{~h}$ of low-flow ischemia did not differ appreciably and have been combined. Although there was a trend toward lower glycogen concentration in the anterior endocardium, there were no significant differences among regions in these 11 studies (all $P>0.10$ ).

Glycogen synthase and phosphorylase activities and regional glycogen synthesis rate. Both anterior and posterior myocardial regions accumulated ${ }^{3} \mathrm{H}$ activity in ethanol-insoluble glycogen during the final hour of ischemia, indicating de novo glycogen synthesis in each region during this period. As shown in Fig. 2, however, synthesis rates were significantly higher in both of the anterior regions and highest in the anterior endocardium.

Paralleling these differences in synthesis rates, the percentage of glycogen synthase present in its physiologically active 
Table III. ${ }^{13} \mathrm{C}$ Enrichment of Plasma Glucose and Myocardial Alanine and Glutamate

\begin{tabular}{|c|c|c|c|c|c|c|}
\hline Region & {$\left[1-{ }^{13} \mathrm{C}\right]$ glucose infusion time } & C-1 glucose (APE) & C-3 alanine (APE) & C-3 alanine/C-1 glucose ratio & C-4 glutamate (APE) & C-4 glutamate/C-3 alanine ratio \\
\hline \multicolumn{7}{|c|}{ Anterior endocardium } \\
\hline & $2 \mathrm{~h}$ & $23.5 \pm 2.8$ & $8.8 \pm 2.9 *$ & $0.37 \pm 0.11^{*}$ & $2.5 \pm 1.3 *$ & $0.28 \pm 0.11$ \\
\hline & $3 \mathrm{~h}$ & 28.0 & 9.7 & 0.35 & 3.5 & 0.36 \\
\hline & $4 \mathrm{~h}$ & 24.0 & 8.7 & 0.36 & 2.5 & 0.29 \\
\hline \multicolumn{7}{|c|}{ Anterior epicardium } \\
\hline & $2 \mathrm{~h}$ & $23.5 \pm 2.8$ & $6.8 \pm 2.3^{*}$ & $0.30 \pm 0.10 *$ & $2.2 \pm 1.0 *$ & $0.32 \pm 0.12$ \\
\hline & $3 \mathrm{~h}$ & 28.0 & 8.9 & 0.32 & 2.6 & 0.29 \\
\hline & $4 \mathrm{~h}$ & 24.0 & 11.2 & 0.47 & 4.2 & 0.31 \\
\hline \multicolumn{7}{|c|}{ Posterior endocardium } \\
\hline & $2 \mathrm{~h}$ & $23.5 \pm 2.8$ & $3.3 \pm 1.5$ & $0.14 \pm 0.05$ & $1.2 \pm 1.0$ & $0.36 \pm 0.15$ \\
\hline & $3 \mathrm{~h}$ & 28.0 & 5.2 & 0.18 & 1.3 & 0.25 \\
\hline & $4 \mathrm{~h}$ & 24.0 & 6 & 0.25 & 1.5 & 0.26 \\
\hline \multicolumn{7}{|c|}{ Posterior epicardium } \\
\hline & $2 \mathrm{~h}$ & $23.5 \pm 2.8$ & $3.5 \pm 1.8$ & $0.15 \pm 0.09$ & $0.9 \pm 1.1$ & $0.26 \pm 0.16$ \\
\hline & $3 \mathrm{~h}$ & 28.0 & 5.7 & 0.20 & 1.0 & 0.18 \\
\hline & $4 \mathrm{~h}$ & 24.0 & 5.5 & 0.23 & 1.6 & 0.28 \\
\hline
\end{tabular}

Fractional ${ }^{13} \mathrm{C}$ enrichment (in APE) of the glucose C- 1 carbon in plasma, and of alanine $\mathrm{C}-3$ and glutamate $\mathrm{C}-4$ carbons in myocardial tissue extracts, after $4 \mathrm{~h}$ of LAD coronary stenosis. Data are mean $\pm \mathrm{SD}$ for eight dogs infused with $\mathrm{D}-\left[1-^{13} \mathrm{C}\right]$ glucose for the final $2 \mathrm{~h}$ of ischemia, two dogs infused for the final $3 \mathrm{~h}$, and one dog infused for $4 \mathrm{~h} . * P<0.05$ vs. values for posterior regions.

GS I form was higher in both endocardial $(46 \pm 10 \%, P<0.01)$ and epicardial $(24 \pm 9 \%, P<0.05)$ layers of the anterior myocardium after 3-4 h of ischemia than in the two posterior regions, whose fractional GS I activity was typical of that usually observed in fasted animals (13 \pm 5 and $9 \pm 6 \%$ ) (Fig. 3). Ischemia did not affect total glycogen synthase or glycogen phosphorylase activities, nor the fraction of phosphorylase activity in the GPa form.

\section{Discussion}

In this study, we infused $\mathrm{D}-\left[1-{ }^{13} \mathrm{C}\right]$ glucose into intact canines at a rate calculated to achieve $20-25 \%$ fractional ${ }^{13} \mathrm{C}$ enrichment in plasma glucose. Under these conditions, intracellular pools of glucose metabolites reach steady state ${ }^{13} \mathrm{C}$ enrichments which are lower than plasma glucose, and whose absolute value is determined by the relative contributions of plasma glucose, versus other precursor molecules, to the pool. Thus, the cytosolic pyruvate pool accumulates $\left[3-{ }^{13} \mathrm{C}\right]$ pyruvate in proportion to the fraction of total glycolytic substrate supplied by exogenous ${ }^{13} \mathrm{C}$-glucose, relative to other carbon sources (e.g., ${ }^{12} \mathrm{C}$-glucose derived from glycogen). Similarly, the steady state ${ }^{13} \mathrm{C}$ enrichment of mitochondrial TCA cycle intermediate compounds is determined by both the relative contribution of plasma glucose to the pyruvate pool and the relative contribution of pyruvate (versus other acetate sources, e.g., fatty acids), to their acetyl-CoA precursor pool. While cellular concentrations of pyruvate and TCA cycle intermediate compounds are generally too low for their ${ }^{13} \mathrm{C}$ enrichments to be measured by ${ }^{13} \mathrm{C}$-NMR spectroscopy, pyruvate and $\alpha$-ketoglutarate are in equilibrium through transaminase reactions with the much larger alanine and glutamate pools. Therefore, measurement of $\left[3-{ }^{13} \mathrm{C}\right]$ alanine and $\left[4-{ }^{13} \mathrm{C}\right]$ glutamate enrichment permits convenient examination of $\left[3-{ }^{13} \mathrm{C}\right]$ pyruvate and $\left[4-{ }^{13} \mathrm{C}\right] \alpha$-ketoglutarate labeling patterns (19-21, 32, 33).
The results of this study demonstrate that under conditions of sustained low-flow ischemia with regional hibernation, glucose imported into the ischemic myocardium from the circulation continues to transit both glycolysis and the TCA cycle to label intracellular pools of alanine and glutamate. Exogenous glucose moreover appears to be the preferred glycolytic substrate in the ischemic myocardium, as indicated by its relatively greater contribution to the cellular alanine pool in ischemic regions. However, there was no difference between ischemic and nonischemic regions in the fraction of total TCA cycle flux supported by glucose-derived pyruvate (i.e., the $\left[4-{ }^{13} \mathrm{C}\right]$ glutamate/[3- $\left.{ }^{13} \mathrm{C}\right]$ alanine enrichment ratio), suggesting that under the conditions of our experiment glucose was not preferred over FFA as an oxidative substrate in the ischemic myocardium. Finally, despite evidence of ongoing ischemia with anaerobic metabolism, imported glucose also continued to enter the glycogen storage pool in the ischemic myocardium. Glycogen synthesis in fact accelerated significantly during ischemia, as a consequence of increased glycogen synthase enzyme activity. Several points are worth making about these observations and about the application of ${ }^{13} \mathrm{C}-\mathrm{NMR}$ methods to this experimental model.

Application of ${ }^{13} C-N M R$ spectroscopy to large animal preparations in vivo. Because NMR spectroscopy is relatively insensitive to the ${ }^{13} \mathrm{C}$ nucleus, examination of metabolic pathways in the heart requires that the fractional ${ }^{13} \mathrm{C}$ enrichment of intermediate compounds first be raised significantly above natural ${ }^{13} \mathrm{C}$ abundance $(\sim 1.1 \%)$. Accomplishing this requires administration of an appreciable mass of ${ }^{13} \mathrm{C}$-labeled substrate, in contrast to the situation with radioactively labeled substrates. For in vivo studies, this may introduce the additional variable of increasing the plasma concentration of the material being administered. This requirement has heretofore limited the use of ${ }^{13} \mathrm{C}-\mathrm{NMR}$ spectroscopy to isolated hearts perfused with defined mixtures of $99 \%$ enriched ${ }^{13} \mathrm{C}$-labeled substrates. In this 


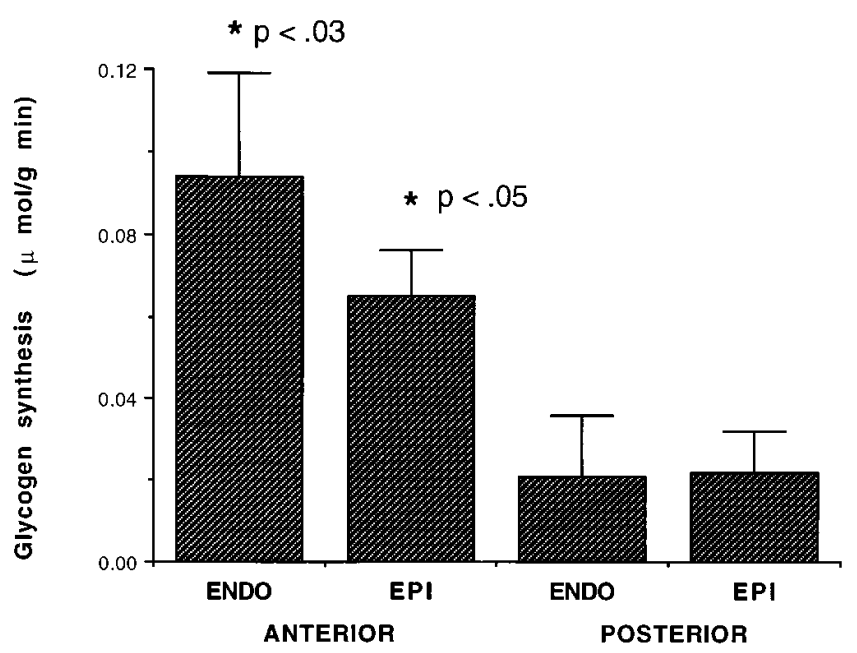

Figure 2. Rates of incorporation of $\mathrm{D}-\left[3-{ }^{3} \mathrm{H}\right]$ glucose from arterial blood into myocardial glycogen during the final hour of LAD stenosis. Values are mean \pm SD for four dogs. Synthesis rates in both anterior regions were greater than in either posterior region of the left ventricle $\left({ }^{*} P<0.05\right)$.

study, by infusing $\mathrm{D}-\left[1-{ }^{13} \mathrm{C}\right]$ glucose at $1.0 \mathrm{mg} / \mathrm{kg} / \mathrm{min}$ we were able to achieve $>20 \%{ }^{13} \mathrm{C}$ enrichment of plasma glucose in intact canines without significantly changing plasma glucose concentration. The resulting ${ }^{13} \mathrm{C}$ enrichments of the spectroscopically accessible intracellular alanine and glutamate pools, while lower than plasma glucose, were nevertheless adequate for analysis. For our purposes, this experimental model offered significant advantages over the study of the isolated heart. It reproduced in the acute setting the characteristic features of chronic hibernation in patients, namely sustained ischemia with contractile arrest but without myocardial necrosis. The use of intact animals allowed myocardial substrate competition to be evaluated under realistic conditions of physiologic work load and whole blood perfusion in vivo. Also, the coronary stenosis model permitted comparison of an ischemic region to normally perfused control regions within the same heart in each experiment.

Glucose metabolism in nonischemic regions of the canine heart. In the 10 dogs studied after 2 or $3 \mathrm{~h}\left[1-{ }^{13} \mathrm{C}\right]$ glucose infusion, the ratio of $\left[3-{ }^{13} \mathrm{C}\right]$ alanine enrichment to simultaneous plasma $\left[1-{ }^{13} \mathrm{C}\right]$ glucose in normally perfused posterior regions of the left ventricle ranged from 0.14 to 0.20 . The theoretical maximum for this ratio, i.e., if the only source of intracellular pyruvate were glycolytic splitting of exogenous glucose, is 0.50 . The observed ratio would be consistent with $28-40 \%$ of myocardial pyruvate being derived from circulating glucose in the canine heart in vivo, with the remainder contributed by other sources (e.g., glycogen, amino acids). This generally agrees with previous observations in the rabbit heart perfused in vitro with $99 \%$ enriched ${ }^{13} \mathrm{C}$-pyruvate $(19,20)$.

As expected, $\left[4-{ }^{13} \mathrm{C}\right.$ ]glutamate fractional enrichment was lower than that of $\left[3{ }^{-13} \mathrm{C}\right]$ alanine in all myocardial regions, reflecting dilution of pyruvate-derived ${ }^{13} \mathrm{C}$-acetyl $\mathrm{CoA}$ by ${ }^{12} \mathrm{C}$-acetyl CoA derived from FFA, before its entry into the TCA cycle. In samples from the nonischemic posterior left ventricle, the ratio of $\left[4-{ }^{13} \mathrm{C}\right]$ glutamate/[3-13 C]alanine enrichment averaged $0.26-0.36$, indicating that glucose-derived pyruvate supports $26-36 \%$ of total TCA cycle flux in the canine heart under

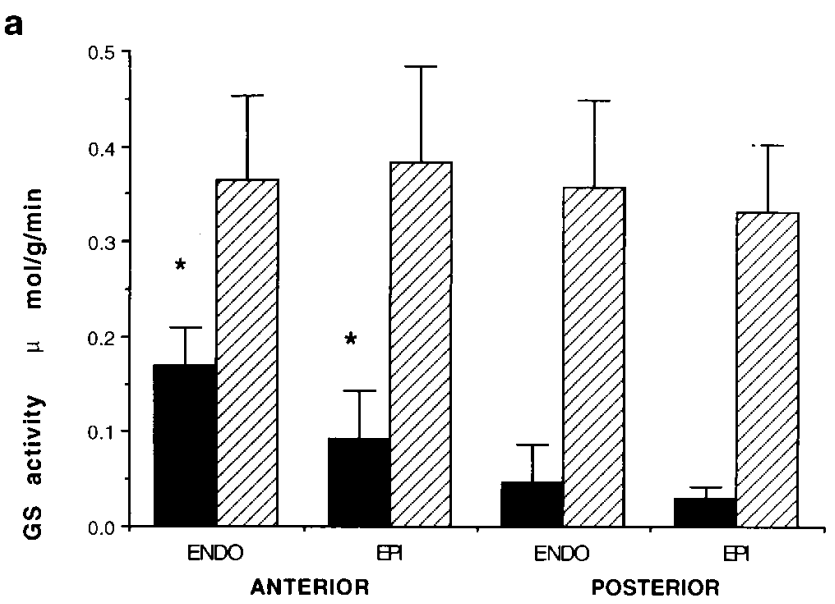

b

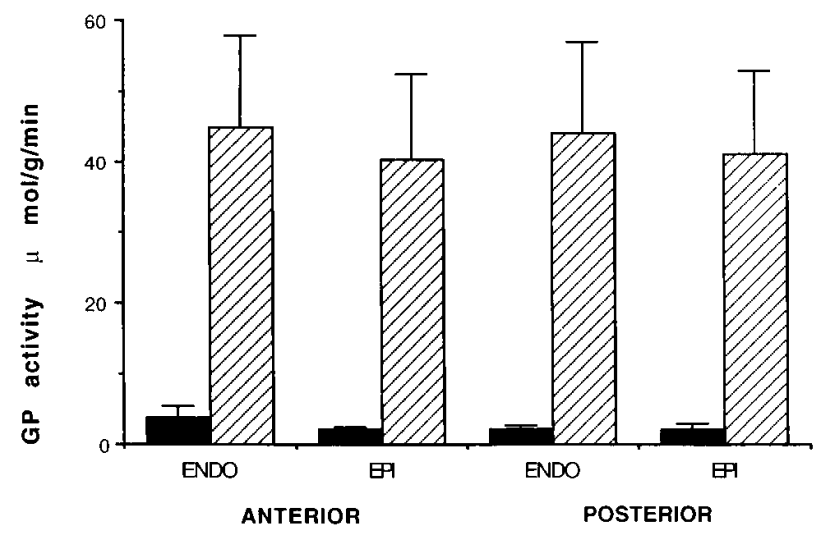

Figure 3. Regional myocardial values for (a) GS I (solid bars) and total glycogen synthase activity (hatched bars) and (b) GPa (solid bars) and total glycogen phosphorylase activity (hatched bars). Data represent mean \pm SD for 11 dogs. GS I activity was significantly $(* P<0.05)$ higher in both endocardial and epicardial regions of the ischemic anterior left ventricle compared with both posterior regions. GPa activity did not differ among the four regions.

physiologic conditions in vivo, with the remainder presumably derived from FFA. Previous studies in isolated hearts perfused in vitro with ${ }^{13} \mathrm{C}$-pyruvate or ${ }^{13} \mathrm{C}$-glucose have generally reported higher values for this ratio $(19,20,32)$. The difference between the current results and previous studies presumably reflects the absence of FFA as a competing substrate in most in vitro experiments, where the heart is typically perfused with crystalloid rather than plasma (9). Indeed, the $\left[4-{ }^{13} \mathrm{C}\right]$ glutamate/[3-13 C]alanine enrichment ratio of the isolated perfused heart has been shown to decrease when palmitate is added to the perfusate (32).

Glucose metabolism in regions of low-flow myocardial ischemia. Compared with normally perfused posterior regions of the left ventricle, anterior regions exhibited significantly higher $\left[3-{ }^{13} \mathrm{C}\right]$ alanine and $\left[4-{ }^{13} \mathrm{C}\right]$ glutamate enrichments. In the anterior endocardium for example, the $\left[3-{ }^{13} \mathrm{C}\right]$ alanine $/\left[1-{ }^{13} \mathrm{C}\right]$ glucose enrichment ratio averaged 0.36 , consistent with $72 \%$ of the tissue pyruvate pool originating from circulating glucose. Weiss (33) has observed a similar increase in $\left[3-{ }^{13} \mathrm{C}\right]$ alanine en- 
richment in the isolated rat heart perfused with $\left[1-{ }^{13} \mathrm{C}\right]$ glucose, upon reducing the perfusion rate by $85 \%$. While this finding was interpreted as a primary effect of ischemia on the rate of pyruvate flux through $\mathrm{PDH}$, at least three alternative explanations might be considered. First, low-flow ischemia might favor glycolytic utilization of exogenous glucose (over glucose derived from endogenous glycogen stores) by stimulating glucose transport, hexokinase activity, or phosphofructokinase activity. A theoretical case can be made for each of these possibilities: for example, reducing the cellular ATP/AMP ratio during ischemia should lower the $K_{\mathrm{m}}$ of phosphofructokinase for its substrate fructose-6-phosphate, thus increasing the glycolytic rate (34). Second, ischemia might reduce or eliminate the contribution of lactate carbon to the pyruvate pool. Third, ischemia might reduce the contribution of glycogen to the cellular glucose-6-phosphate pool, either by inhibiting glycogenolysis directly or by stimulating hexokinase-catalyzed phosphorylation of imported glucose. This third alternative would be consistent with the recent observation of Janvier (35) that moderate ischemia inhibits glycogen breakdown in the isolated rabbit heart, while accelerating glycolytic utilization of exogenous glucose. The current data do not allow these alternative possibilities to be clearly distinguished. However, to the extent that they may be interpreted as showing preferred glycolytic utilization of exogenous glucose in the hibernating myocardium, they may be important; both Janvier (35) and Runnman (36) have observed that hearts using exogenous glucose as their primary glycolytic substrate appear better protected from the effects of ischemia in vitro than hearts using glucose liberated from endogenous glycogen.

As shown in Table III, low-flow ischemia did not appear to affect the steady state $\left[4-{ }^{13} \mathrm{C}\right]$ glutamate/[3-13 C]alanine ratio of the myocardium, indicating that there was no increased preference for glucose as an oxidative fuel in acutely hibernating regions of the canine heart.

Glycogen metabolism during low-flow myocardial ischemia. Somewhat surprisingly, after 3-4 h of low-flow ischemia the glycogen concentration of the anterior endocardium was only minimally lower than those of posterior control regions. Although cardiac glycogen is usually assumed to be quickly mobilized during severe cellular anoxia, its persistence during moderate ischemia is apparent (though not explained) in previous studies by others. For example, Schulz observed that during $90 \mathrm{~min}$ of moderately severe (subendocardial blood flow $\sim 0.2 \mathrm{ml} / \mathrm{gram} / \mathrm{min}$ ) regional ischemia in swine, the glycogen concentration of the ischemic region fell $30 \%$ during the first $5 \mathrm{~min}$, but did not fall further during the subsequent 85 min (5). In our study, glycogen persistence in ischemic regions was associated with proportionate increases in both the activity of the physiologically active GS I form of glycogen synthase and the rate of incorporation of circulating glucose into glycogen in vivo during the final hour of low-flow ischemia. Recently, we have observed similar regional activation of myocardial glycogen synthase after transient coronary artery occlusion with regional glycogen depletion in the rat (25). However, in that setting glycogen synthase activation persisted for only $\sim 45 \mathrm{~min}$, similar to the response to insulin administration. In the current study GS I activity was higher in ischemic than in normally perfused regions of the canine left ventricle 3-4 h into LAD stenosis, suggesting that low-flow ischemia may induce persistent regional myocardial glycogen synthase activation. Although we measured glycogen concen- tration and synthesis rate only during the latter stages of these experiments, our observations would fit a scenario in which glycogen consumption early during low-flow ischemia activates glycogen synthase, thus accelerating glycogen synthesis and returning glycogen content toward normal levels. Longer observation periods will be required to determine whether persistent glycogen synthase activation can produce the supernormal glycogen concentrations observed in noncontracting segments of the human heart (15-17). In previous studies in rats, ischemic glycogen synthase activation was attributed to the effect of increased myocardial glucose-6-phosphate concentration on a glycogen synthase phosphatase (25). Glucose6-phosphate concentrations were measured in extracts of frozen canine myocardium in the current study, but did not differ among regions and were uniformly high (0.3-0.4 $\mu \mathrm{mol} / \mathrm{gram})$, probably because these larger tissue samples could not be frozen as quickly as the smaller rat heart.

Limitations. Our study design permitted tissue metabolite pools to be examined only at the end of each experiment. This design feature imposed both a technical and a biological limitation. First, the time course of ${ }^{13} \mathrm{C}$ equilibration between glucose, alanine, and glutamate pools could not be assessed in individual hearts. Theoretically, slower rates of TCA cycle activity in ischemic regions could prolong the time needed to reach steady state $\left[4-{ }^{13} \mathrm{C}\right]$ glutamate $/\left[3{ }^{13} \mathrm{C}\right]$ alanine enrichment ratio, leading to underestimation of the ratio in those regions (37). We chose a 2 -h infusion time for $\mathrm{D}-\left[1-{ }^{13} \mathrm{C}\right]$ glucose because hearts perfused in vitro with ${ }^{13} \mathrm{C}$-glucose are reported to reach steady state ${ }^{13} \mathrm{C}$ enrichment in tissue alanine and glutamate pools within $30 \mathrm{~min}(33,37)$. Extending the period of $\left[1-{ }^{13} \mathrm{C}\right]$ glucose infusion to 3 or $4 \mathrm{~h}$ did not significantly increase the $\left[4-{ }^{13} \mathrm{C}\right]$ glutamate $/\left[3-{ }^{13} \mathrm{C}\right]$ alanine enrichment ratio in the ischemic region, suggesting that 2-h measurements were indeed made at steady state.

A more general point is that our observations predominantly reflect the metabolic state of the myocardium toward the end of each experiment. Experience with related experimental models would in fact predict that conditions in the ischemic risk area distal to the LAD stenosis might change substantially during prolonged low flow. Specifically, downregulation of energy use, and potentially other metabolic adjustments associated with the establishment of the hibernating state, may have significantly ameliorated the degree of cellular ischemia within the LAD coronary region by the end of the 3-4-h low-flow period. Consequently, our observations may be more pertinent to the condition of myocardial hibernation than myocardial ischemia. In future studies, serial nondestructive NMR spectroscopic examinations of the ischemic region in vivo should yield a better understanding of the metabolic adaptation to prolonged reduction in coronary flow.

Summary. Regions of the canine heart perfused through a stenotic coronary artery lose the ability to contract and demonstrate adaptive changes in glucose metabolism, including increased glycolytic utilization of exogenous glucose and increased glucose storage. These changes are most prominent in the ischemic endocardial layer of the heart but are expressed transmurally, suggesting that transmural contractile arrest may alter glucose metabolism even in epicardial layers where blood flow is preserved. Glucose flux through PDH continues to support less than one-third of total oxidative metabolism however even when myocardial blood flow is reduced by $60 \%$. These observations demonstrate the feasibility of using ${ }^{13} \mathrm{C}-\mathrm{NMR}$ to 
study substrate utilization in the hearts of intact large animals and suggest that ${ }^{13} \mathrm{C}$-NMR spectroscopy may allow unique insights into the metabolic adaptation to myocardial ischemia in vivo.

\section{Acknowledgments}

This work was supported by National Institutes of Health grants RO1 DK-40936 and PO1 DK-45735, by a Grant-in-Aid from the American Heart Association Connecticut Affiliate, and by a Merit Review grant from the Department of Veterans Affairs. Dr. McNulty is a Clinician-Scientist Awardee of the American Heart Association (AHA 91004370)

\section{References}

1. Braunwald, E., and J.D. Rutherford. 1986. Reversible ischemic left ventricular dysfunction: evidence for the "hibernating" myocardium. J. Am. Coll. Cardiol. 8:1467-1470.

2. Arai, A.E., S.E. Graur, C.G. Anselone, G.A. Pantely, and J.D. Bristow. 1995. Metabolic adaptation to a gradual reduction in myocardial blood flow. Circulation. 92:244-252.

3. Arai, A.E., G.A. Pantely, C.G. Anselone, J. Bristow, and J.D. Bristow. 1991. Active downregulation of myocardial energy requirements during prolonged moderate ischemia in swine. Circ. Res. 69:1458-1469.

4. Schaefer, S., G. Schwartz, J.A. Wisneski, S.D. Trocha, I. Christoph, S.K. Steinman, J. Garcia, B.M. Massie, and M. Weiner. 1992. Response of highenergy phosphates and lactate release during prolonged regional ischemia in vivo. Circulation. 85:342-349.

5. Schulz, R., J. Rose, C. Martin, O.-E. Brodde, and G. Heusch. 1993. Development of short-term myocardial hibernation. Its limitation by the severity of ischemia and ionotrophic stimulation. Circulation. 88:684-695.

6. Ito, B. 1995. Gradual onset of myocardial ischemia results in reduced myocardial infarction associated with reduced contractile function and metabolic downregulation. Circulation. 91:2058-2070.

7. Fedele, F.A., H. Gewirtz, R.J. Cappone, B. Sharaf, and A.S. Most. 1988. Metabolic response to prolonged reduction of myocardial blood flow distal to a severe coronary artery stenosis. Circulation. 78:729-735.

8. Liedtke, A.J. 1981. Alterations in carbohydrate and lipid metabolism in the acutely ischemic heart. Prog. Cardiovasc. Dis. 23:321-326.

9. Tamm, C., R. Benzi, I. Papageorgiou, I. Tardy, and R. Lerch. 1994. Substrate competition in postischemic myocardium. Effect of substrate availability during reperfusion on metabolic and contractile recovery in isolated rat hearts. Circ. Res. 75:1103-1112.

10. Schwaiger, M., R.A. Neese, L. Araujo, W. Wyns, J.A. Wisneski, H. Sochor, S. Swank, D. Kulber, C. Selin, M. Phelps, et al. 1989. Sustained nonoxidative glucose utilization and depletion of glycogen in reperfused canine myocardium. J. Am. Coll. Cardiol. 13:745-754.

11. Tillish, J., R. Brunken, R. Marshall, M. Schwaiger, M. Mandelkern, M. Phelps, and H. Schelbert. 1986. Reversibility of cardiac wall-motion abnormalities predicted by positron tomography. N. Engl. J. Med. 314:884-888.

12. Brunken, R., J. Tillish, M. Schwaiger, J. Child, R. Marshall, M. Mandelkern, M. Phelps, and H. Schelbert. 1986. Regional perfusion, glucose metabolism and wall motion in electrocardiographic Q-wave infarctions: evidence for persistence of viable tissue in some infarct regions by positron emission tomography. Circulation. 73:951-963.

13. Xu, K.Y., J.L. Zweier, and L.C. Becker. 1995. Functional coupling between glycolysis and sarcoplasmic reticulum $\mathrm{Ca}^{2+}$ transport. Circ. Res. 77:88-97.

14. Weiss, J., and H. Hiltbrand. 1985. Functional compartmentation of glycolytic versus oxidative metabolism in isolated rabbit heart. J. Clin. Invest. 75: 436-447.

15. Depre, C., J.-L. Vanoverschelde, J.A. Melin, M. Borgers, A. Bol, J. Ausma, R. Dion, and W. Wijns. 1995. Structural and metabolic correlates of the reversibility of chronic left ventricular ischemic dysfunction in humans. Am. J. Physiol. 268:H1265-H1275.

16. Maes, A., W. Flameng, J. Nuyts, M. Borgers, B. Shivalkar, J. Ausma, G.
Bormans, C. Schiepers, M. De Roo, and L. Mortelmans. 1994. Histological alterations in chronically hypoperfused myocardium. Correlation with PET find ings. Circulation. 90:735-745.

17. Vanoverschelde, J.-L., W. Wijns, C. Depre, B. Essamri, G. Heyndrickx, M. Borgers, A. Bol, and J.A. Melin. 1993. Mechanisms of chronic regional postischemic dysfunction in humans: new insights from the study of non-infarcted collateral dependent myocardium. Circulation. 87:1513-1523.

18. Weiss, R.G., V.P. Chacko, and G. Gerstenblith. 1989. Fatty acid regulation of glucose metabolism in the intact beating rat heart assessed by carbon-13 NMR spectroscopy: the critical role of pyruvate dehydrogenase. J. Mol. Cell. Cardiol. 21:469-478.

19. Lewandoski, E.D., and L.T. White. 1995. Pyruvate dehydrogenase influences postischemic heart function. Circulation. 91:2071-2079.

20. Lewandoski, E.D. 1992. Metabolic heterogeneity of carbon substrate utilization in mammalian heart: NMR determinations of mitochondrial versus cytosolic compartmentation. Biochemistry. 31:8916-8923.

21. Shulman, G.I., L. Rossetti, D.L. Rothman, J.B. Blair, and D. Smith 1987. Quantitative analysis of glycogen repletion by nuclear magnetic resonance spectroscopy in the conscious rat. J. Clin. Invest. 80:387-393.

22. Kobayashi, K., and J.R. Neeley. 1983. Effects of ischemia and reperfusion on pyruvate dehydrogenase activity in isolated rat hearts. J. Mol. Cell. Cardiol. 15:359-367.

23. Lewandowski, E.D., and D.L. Johnston. 1990. Reduced substrate oxidation in postischemic myocardium: ${ }^{13} \mathrm{C}$ and ${ }^{31} \mathrm{P}$ NMR analyses. Am. J. Physiol. 258:H1357-H1365.

24. Shi, C.Q.-X., A.J. Sinusas, D.P. Dione, M.J. Singer, L.H. Young, E.N. Heller, B.D. Rinker, F.J. Wackers, and B.L. Zaret. 1995. Technetium-99mnitroimidazole (BMS181321): a positive imaging agent for detecting myocardial ischemia. J. Nucl. Med. 36:1078-1086.

25. McNulty, P.H., and M.C. Luba. 1995. Transient ischemia induces regional myocardial glycogen synthase activation and glycogen synthesis in vivo. Am. J. Physiol. 268:H364-H370.

26. McNulty, P.H., W.X. Liu, M.C. Luba, J.A. Valenti, G.V. Letsou, and J.C. Baldwin. 1995. Effect of non-working heterotopic transplantation on rat heart glycogen metabolism. Am. J. Physiol. 268:E48-E54.

27. Sinusas, A.J., J.D. Bergin, N.C. Edwards, D.D. Watson, M. Ruiz, R.W Makuch, W.H. Smith, and G.A. Beller. 1994. Redistribution of ${ }^{99 \mathrm{~m} T c-S e s t a m i b}$ and ${ }^{201} \mathrm{Tl}$ in the presence of a severe coronary artery stenosis. Circulation. 89: 2332-2341.

28. Kunst, A., B. Draeger, and J. Ziegenhorn. 1984. D-glucose. UV-methods with hexokinase and glucose-6-phosphate dehydrogenase. In Methods of Enzymatic Analysis. 3rd edition. H.U. Bergmeyer, editor. Verlag Chemie, Weinheim, Germany. 163-172.

29. Leimer, K.R., R.H. Rice, and C.W. Gehrke. 1977. Complete mass spectra of $N$-trifluoroacetyl- $n$-butyl esters of amino acids. J. Chromatogr. 141:121144

30. Thomas, J.A., K.K. Schlender, and J. Larner. 1968. A rapid filter paper assay for UDP glucose-glycogen glucosyltransferase, including an improved biosynthesis of UDP-14 C-glucose. Anal. Biochem. 125:486-499.

31. Tan, A.W.H., and F.Q. Nuttal. 1975. Characteristics of the dephosphorylated form of phosphorylase purified from rat liver and measurement of its activity in crude liver preparations. Biochem. Biophys. Acta. 410:45-60.

32. Johnston, D.L., and E.D. Lewandowski. 1991. Fatty acid metabolism and contractile function in the reperfused myocardium: multinuclear NMR studies of isolated rabbit hearts. Circ. Res. 68:714-725.

33. Weiss, R.G., V. Chacko, J. Glickson, and G. Gerstenblith. 1989. Comparative ${ }^{13} \mathrm{C}$ and ${ }^{31} \mathrm{P}$ NMR assessment of altered metabolism during graded reductions in coronary flow in intact rat hearts. Proc. Natl. Acad. Sci. USA. 86: 6426-6430.

34. Randle, P.J. 1976. Regulation of glycolysis and pyruvate oxidation in cardiac muscle. Circ. Res. 38(Suppl. 1):I8-I15.

35. Janvier, M.F., J.-L. Vanoverschelde, and S.R. Bergmann. 1994. Ischemic preconditioning stimulates anaerobic glycolysis in the isolated rabbit heart. Am. J. Physiol. 267:H1353-H1360.

36. Runnman, E.M., S.T. Lamp, and J.N. Weiss. 1990. Enhanced utilization of exogenous glucose improves cardiac function in hypoxic rabbit ventricle without increasing total glycolytic flux. J. Clin. Invest. 86:1222-1233.

37. Weiss, R.G., S.T. Goth, R. Kalil-Filho, V. Chacko, M. Stern, and G. Gerstenblith. 1992. Indexing tricarboxylic acid flux in intact hearts by carbon-13 nuclear magnetic resonance. Circ. Res. 70:392-408. 